\title{
INTERESES OCULTOS EN EL ORIGEN De la Segunda Guerra Mundial
}

\author{
HIDDEN INTERESTS IN THE ORIGIN \\ OF THE SECOND WORLD WAR
}

JOSÉ SALGADO DEFRANC

Universidad Tecnológica Equinoccial

Correo electrónico: esalgado@ute.edu.ec
FECHA DE RECEPCIÓN: 05/05/2016

FECHA DE ACEPTACIÓN: 05/06/2016

\section{RESUMEN}

En la Segunda Guerra Mundial fallecieron más de 60 millones de personas. El origen de esta guerra es el tema de estudio del presente artículo. El origen de la guerra no se lo tiene que buscar en las complejas sicologías de nefastos personajes como Hitler, Goebels, Goering o Himmler. Los verdaderos orígenes están vinculados a profundos intereses financieros de empresas anglosajonas. El objetivo más importante era apoderarse de la riqueza petrolera y minera de la Unión Soviética. Estos intereses se cruzaban con los de potencias hegemónicas que buscaban la destrucción de la Unión Soviética, de Alemania y en general de la Europa Continental. En este caso, el objetivo era que los Estados Unidos se consolide como la primera potencia mundial. Además, Inglaterra se beneficiaba enormemente con el debilitamiento de sus principales rivales en la Europa Continental: Alemania y Francia. En este artículo se devela la existencia de personajes oscuros como Hjalmar Schacht (presidente del Reichbank y Ministro de Economía del gobierno de Hitler) y Lord Montagu Norman, gobernador del Banco de Inglaterra.

Palabras clave: Segunda Guerra Mundial, Farbenindustrie A.G., Hjalmar Schacht, Montagu Norman, Rockefeller.

\begin{abstract}
In World War II, more than 60 million people died. The origin of this War is the subject of study of this article. The origin of the war should't be searched in the complex psychologies of nefarious personages like Hitler, Goebels, Goering, Himmler. The true origins are linked to the deep financial interest of Anglo-Saxon companies. The main objective was to seize the oil and mining wealth of the Soviet Union. These interests intersected with those of hegemonic powers that sought the destruction of the Soviet Union, Germany and the entire Continental Europe. In this case, the goal was for the United States to become the first world power. England benefited greatly from the weakening of its main rivals in Continental Europe: Germany and France. This article reveals the existence of dark characters such as Hjalmar Schacht (President of the Reichbank and Minister of Economy of Hitler's Government) and Lord Montagu Norman (Governor of the Bank of England).
\end{abstract}

Keywords: Second World War, Farbenindustrie A.G., Hjalmar Schacht, Montagu Norman, Rockefeller. 


\section{Introducción}

El siglo XX fue testigo de dos guerras mundiales, la Primera llevada a cabo entre el 28 de julio de 1914 y el 11 de noviembre de 1918 y la Segunda entre el 1 de septiembre de 1939 y el 8 de mayo de 1945. El Tratado de Versalles, firmado en la Galería de los Espejos el 28 de junio de 1919, selló formalmente la finalización de la Primera Guerra Mundial y fue, sin duda alguna, el inicio de la Segunda Guerra Mundial. Las razones fueron advertidas por el economista inglés John Maynard Keynes ${ }^{1}$, quien se percató que la humillación que significaban para Alemania los términos del Tratado de Versalles, haría surgir en este país un peligroso sentimiento revanchista.

Paradójicamente, uno de los principales ideólogos del sentimiento expansionista alemán había fallecido en 1900. Nos referimos a Friedrich Nietzsche ${ }^{2}$, quién en su obra más importante titulada La voluntad del poder desarrolló el peligroso concepto de espacio vital ${ }^{3}$. Nietzsche fue algo así como el ideólogo de Guillermo Segundo y posteriormente de los nacional socialistas.

Hitler fue nombrado canciller por Hindenburg el 30 de enero de 19334. Espacio vital hacia el este de Alemania era su objetivo visible. El primer momento de esta expansión fue la anexión de la región del Sarre el 17 de enero de $1935^{5}$. El segundo momento fue la anexión de Austria el 12 de marzo de 1938. El canciller austríaco Schuschigg solicitó ayuda a Francia e Inglaterra. Estos dos países se negaron a impedir el Anschluus de Hitler ${ }^{6}$. (Brook, enero 1977)

El tercer momento merece un párrafo aparte. Nos referimos al Acuerdo de Múnich. En el Acuerdo de Múnich, Francia e Inglaterra convalidaron la anexión por parte de Alemania de los Sudetes en Checoslovaquia ${ }^{7}$. Este Acuerdo se firmó el 30 de septiembre de 1938 y Alemania se comprometió a no avanzar más. La promesa, por supuesto, no se cumplió y el resto de Checoslovaquia fue anexada el 15 de marzo de 1939.

Es indiscutible que Occidente empujaba a Alemania hacia el este. La Unión Soviética ante este acorralamiento se vio en la necesidad de firmar el acuerdo entre Ribbentrop y Mólotov ${ }^{8}$. La URSS buscaba ganar tiempo, pues era evidente que sería invadida en momentos sucesivos del expansionismo alemán. Si desde el punto de vista estratégico fue lo correcto para la Unión Soviética es un punto a discutirse, pues con este Pacto, Alemania pudo invadir Polonia y de esta manera ya tener fronteras con la Unión Soviética. La Guerra comenzó el primero de septiembre de 1939. La invasión a la URSS, verdadero objetivo de Hitler, se llevó a cabo el 22 de junio de 1941. En la guerra la Unión Soviética perdió 27 millones de hombres y Alemania 13'600.000. (Soloviov, 1988)

1 Keynes asistió al Tratado de Versalles en representación del gobierno inglés, sin embargo de lo cual se negó a firmar y convalidar lo resuelto en este Tratado. (Keynes, junio de 2002)

2 En rigor, el pensamiento de Nietzsche era una respuesta a la tardía unificación alemana (recordemos que recién en 1871 surge el Estado alemán). La Alemania de fines del siglo XIX y comienzos del XX urgía de una reconfiguración geográfica del mundo colonial. Necesita colonias para extraer materias primas y colocar los productos de su poderosa industria. (Nietzsche, abril 2009)

3 El espacio vital Nietzsche describe y explica a partir de dos términos más peligrosos todavía: conservación y aumento. El libro de Nietzsche fue de lectura obligatoria durante el Tercer Reich.

4 Debe quedar claro ante la historia que Hitler nunca ganó una elección. La última en la que participó en noviembre de 1932 supuso una derrota contundente. El ascenso de Hitler al poder más tiene que ver con un golpe de Estado preparado al otro lado del Atlántico.

5 En los acuerdos de Versalles la región del Sarre fue entregada a la administración de la Sociedad de Naciones. En los acuerdos se había previsto que en 15 años se llevaría a cabo un referéndum para que la población decida su futuro. La población mayoritariamente decidió pasar a formar parte de Alemania.

6 Era por demás evidente la estrategia de Francia e Inglaterra de dirigir a los nazis hacia el este. La Unión Soviética era el verdadero objetivo de unos y otros.

7 El acuerdo de Múnich fue por demás vergonzoso. No se invitó al gobierno checoeslovaco ni al gobierno soviético. La decisión la tomaron Inglaterra, Francia, Italia y Alemania.

8 El Acuerdo se firmó el 23 de agosto de 1939. 


\section{Desarrollo}

Han pasado setenta años desde la finalización de la Segunda Guerra Mundial, y a pesar que existe una cantidad variopinta de interpretaciones, lo cierto es que el estudio de cuáles fueron las causas ocultas que desencadenaron este conflicto, parecería que recién está tomando forma. Sucede que las interpretaciones desde la economía política siempre tardan en aparecer. Intereses ocultos se metamorfosean de mil maneras, pretenden, en este caso, encubrir la responsabilidad por la muerte de más de sesenta millones de seres humanos.

Investigaciones realizadas en años recientes demuestran que la Segunda Guerra Mundial no se originó producto de obsesiones patológicas de Adolfo Hitler. Según Valentin Katasonov, la Segunda Guerra Mundial fue obra de una oligarquía mundial, o más exactamente de plutócratas anglo-estadounidenses. Dicho autor seńala que

"Detrás de aquel complot se hallaban personajes claves: los Rockefeller, los Morgan, Lord Montagu Norman (gobernador del Banco de Inglaterra) y Hjalmar Schacht (presidente del Reichbank y Ministro de Economía del gobierno de Hitler). El programa estratégico de los Rockefeller y los Morgan era sojuzgar Europa económicamente, saturar Alemania de inversiones y créditos extranjeros y empujarla a asestar un golpe mortal a la Rusia soviética para que esta última volviese al capitalismo, en calidad de colonia" (Katasonov, 2015).

En semejante entuerto, Montagu Norman fue el intermediario en las conversaciones entre grupos financieros estadounidenses y los directores de empresas alemanas. Personaje fundamental en Alemania fue Hjalmar Schacht, quien "organizó la reconstrucción del sector vinculado a la defensa en la economía alemana. La operación de los plutócratas contaba con la cobertura que le ofrecían políticos como Franklin Roosevelt, Neville Chamberlain y Winston Churchill. En Alemania los ejecutores de aquellos proyectos eran Hitler y Hjalmar Schacht. Según varios historiadores, Hjalmar Schacht desempeñó un papel más im- portante que Hitler, pero se mantenía en la sombra” (Katasonov, 2015).

Debido a la importancia de la información que proporciona Valentin Katasonov, procedemos a citar in extenso varios párrafos de su artículo:

"El capital de la mayoría de las empresas alemanas estratégicamente importantes era, parcial o completamente, estadounidense. Una parte estaba bajo control de los inversionistas británicos. Los sectores de la economía alemana como las refinerías de petróleo, el proceso de licuefacción de carbón estaban en manos de Standard Oil, perteneciente a los Rockefeller. El gigante de la industria química Farbenindustrie AG pasó al control del grupo Morgan. Un $40 \%$ de la red telefónica y un 30\% de las acciones de Focke Wulf se hallaban bajo control de la firma estadounidense ITT. La radio y los gigantes de la industria eléctrica AEG, Siemens y Osram pasaron al control de General Electric, de Estados Unidos. ITT y General Electric eran parte del imperio Morgan. El 100\% de las acciones de Volkswagen pertenecía a Ford, también de Estados Unidos...”

"Los grandes bancos alemanes, como el Deutsche Bank, el Dresdner Bank, el Donat Bank y otros, se hallaban bajo control estadounidense..."

"El 30 de enero de 1933, Hitler se convertía en canciller de Alemania. Pero antes, los banqueros estadounidenses habían estudiado muy cuidadosamente su candidatura. Hjalmar Schacht había viajado a Estados Unidos durante el otońo de 1930 para hablar de aquella nominación con varios colegas estadounidenses. La designación de Hitler fue aprobada finalmente durante una reunión secreta de personalidades de las finanzas en Estados Unidos..."

"A mediados de noviembre de 1932, 17 de los más poderosos banqueros e industriales alemanes dirigieron al presidente Hindenburg una carta exigiéndole que nombrara canciller 
a Hitler. La última reunión de trabajo de los financieros alemanes previa a la elección tuvo lugar el 4 de enero de 1933 en Colonia, en la residencia del banquero Kurt von Schroder. El partido nazi llegó al poder inmediatamente después. Las relaciones financieras y económicas de Alemania con los anglosajones se hicieron aún más estrechas" (Katasonov, 2015).

Cuando Hitler fue nombrado canciller, el general Ludendorff, quien se percató del error histórico que estaba cometiendo, le envió a Hindenburg una misiva en la que le decía: "Al nombrar a Hitler canciller del Reich, Ud., entregó nuestra patria alemana a uno de los más grandes demagogos de todos los tiempos. Yo con toda seguridad le predigo que este hombre llevará a nuestro país al precipicio, envolverá a nuestra nación en una infelicidad indescriptible. Las futuras generaciones lo maldecirán a Ud., por lo que ha hecho" (Bueno, 1985).

Una de las razones que explica la geopolítica de Inglaterra y los Estados Unidos radica en que desde 1932 la Unión Soviética había comenzado a implementar planes quinquenales de desarrollo. El desarrollo de este país era vertiginoso, sobre todo en lo que tiene que ver con la industria pesada. Mientras esto sucedía en la URSS, el New Deal que implementó Roosevelt en los Estados Unidos había fracasado?. En 1939 la tasa de desempleo en este país era del 17,2\% (Dornbusch, Stanley, \& Richard, 2002). La única solución para los Estados Unidos era una guerra lejos de su territorio. Además, y lo señala muy bien Carlos de Nápoli, otro de los objetivos era controlar "los pozos petroleros de la zona más rica por entonces conocida: el Cáucaso y Medio Oriente" (De Nápoli, 2015).

En coincidencia con las investigaciones de Valentin Katasonov, el intelectual argentino Carlos de Nápoli señala: "Cuando el 22 de junio de 1941 Adolf Hitler ordenó el comienzo de la invasión a la Unión Soviética, estaba desatando fuerzas que ya no estarían bajo su control. Ese paso, confuso para la mayoría, respondía en última instancia a los intereses de un puñado de poderosos petroleros e industriales que, si todo salía bien, controla- ría en breve la economía del mundo" (De Nápoli, 2015).

Para comprender la política ${ }^{10}$ de la dupla Estados Unidos - Inglaterra, es condición sine qua non desentrañar los intereses geopolíticos de estos dos países y simultáneamente los intereses económicos de sus poderosas multinacionales. Percibir estas aristas por separado o solo una de ellas (sea la una o la otra), es condenarse a no comprender la sutileza con que manejan su política estos dos países.

Harry S. Truman ${ }^{11}$, dos días después de la ejecución del Plan Barbarroja, expresó el juego de intereses de ese país cuando el 24 de junio de 1941 -en una declaración al New York Timescomentó: "si vemos que gana Alemania, entonces debemos ayudar a Rusia, y si comienza a ganar Rusia, entonces debemos ayudar a Alemania, y de esta manera, ojala se maten entre ellos, entre más mejor" (Bueno, 1985).

Asimismo, para comprender los intereses económicos de las multinacionales norteamericanas es imprescindible investigar el papel que jugaron los intereses de la IG Farbenindustrie AG.

Cabe recordar que Alemania (y no por coincidencia Italia y Japón también) no poseía reservas de petróleo, además "Las restricciones del tratado de Versalles hacían imposible acceder a colonias o reservas de petróleo, por lo cual la denominada República de Weimar decidió apoyar la creación de una enorme petroquímica: IG Farbenindustrie AG. Ese gigantesco monopolio debía producir la mayor cantidad posible de bienes a partir del carbón como base para la producción de energía.

9 La Gran Depresión azotó la economía norteamericana desde 1929. "La Gran Depresión en Estados Unidos se terminó gracias a un programa enorme de obras públicas financiado con déficit. Dicho programa se conoce con el nombre de Segunda Guerra Mundial”. (Krugman, 1999)

10 La política es, posiblemente, la abstracción de más difícil comprensión en el interior de las ciencias sociales.

11 En ese entonces senador. 
Uno de los procesos, inventado por el químico Friedrich Bergius, permitía obtener por hidrogenación del carbón combustibles sintéticos de acto octanaje, un producto muy apto para los motores de aviación”.

"Por otra parte la IG Farbenindustrie AG obtuvo caucho sintético mediante una mezcla de carbón, cal y otros productos a altas presiones y temperaturas..."

"Como no podía ser de otra manera, la Standar Oil de New Jersey se enteró de los planes de la Farbenindustrie de producir combustible sintético. Walter C. Teagle, presidente de la Standard, Henry Ford y varios de los más importantes empresarios de los Estados Unidos se unieron para proporcionar a la Farben el capital necesario para el desarrollo de los inventos que por entonces eran primitivos resultados de laboratorio" (De Nápoli, 2015).

En esas condiciones, fácil es entender como la Farbenindustrie comenzó a gravitar en el desarrollo de la política socioeconómica de Alemania, "tanto que financiaron con cifras elevadas la carrera política de Adolf Hitler... En ese inmenso monopolio se ideó, planeó y concretó cada paso de Hitler, desde la financiación de su vertiginoso ascenso al poder, hasta su desaparición" (De Nápoli, 2015).

Indica De Nápoli que en los juicios de Núremberg quedo probada "la alianza entre la IG Farben y el partido nazi, la sincronización de las actividades de la empresa y el Alto Mando Alemán, su participación en el desarrollo del Plan Cuatrienal -de economía de guerra-, en actividades de propaganda, inteligencia y espionaje”.

El 100 por ciento del combustible, el 80 por ciento de los explosivos y el 90 por ciento del caucho para cubiertas de vehículos y para usos industriales provenía de la IG Farbenindustrie AG. Asimismo la empresa producía medicamentos y todo tipo de gases industriales y venenosos, incluido el Zyklon-B que se usó para asesinar a millones de personas en campos de concentración y exterminio.
Con todos estos antecedentes, Carlos de Nápoli señala que "Es evidente que si las cosas hubieran resultado de acuerdo con lo planeado... la IG Farben, la Standard Oil of New Jersey y la Ford Motor Company habrían logrado el monopolio casi absoluto tanto de las reservas mundiales de petróleo como de la producción de combustibles y aceites sintéticos, además del caucho artificial que tanto obsesionaba a Henry Ford...Lo que la invasión buscaba era el monopolio petrolero con sus socios americanos, entre ellos Henry Ford y Walter Teagle de la Standar Oil”. (De Nápoli, 2015)

Otro testimonio de las imbricaciones que existían entre el alto mando anglosajón y poderosos intereses de empresas norteamericanas, lo hemos encontrado en las Memorias y Reflexiones del mariscal soviético G.K. Zhukov. Con la finalidad de ubicar el contexto recordemos que el Segundo Frente entró en acción cuando la Guerra entraba en su etapa final. Efectivamente, el frente que debía enfrentar a Alemania desde el oeste de este país recién fue abierto el 6 de junio de $1944^{12}$. En este caso, la intervención de las fuerzas aliadas en gran parte consistió en bombardeos aéreos. Estos bombardeos en ningún caso afectaron las instalaciones de la Farbenindustrie. Citemos textualmente el relato del mariscal soviético sobre este hecho particular.

"El EM de Eisenhower hallábase instalado en los gigantescos edificios del consorcio químico IG Farbenindustrie, que habían quedado indemnes después de los devastadores bombardeos de Fráncfort, pese que a la ciudad había sido trasformada en una escombrera por la aviación de los aliados" (Zhukov, 1971)

"Es revelador que también en otras zonas de Alemania los establecimientos del Farbenindustrie habían quedado incólumes, aunque era un espléndido objetivo para los bombardeos. No cabe duda que a este propósito al mando de los aliados le fueron dadas especia-

12 Oficialmente la Segunda Guerra Mundial finalizó el 8 de mayo de 1945. 
les indicaciones desde Washington y Londres" (Zhukov, 1971)

"Importa decir que muchas otras fábricas de guerra supervivieron también en Alemania Occidental. Como se aclaró luego, los hilos financieros de estas grandes empresas bélicas conducían hacia los monopolios de Norteamérica y la Gran Bretaña”. (Zhukov, 1971)

Para terminar con estas breves reflexiones sobre las verdaderas causas que originaron la Segunda Guerra Mundial, se debe indicar un dato que ha pasado desapercibido en los estudios que se han realizado sobre este tema, y es, que el alto mando alemán no consideraba conveniente que su país tuviese que afrontar una nueva guerra. Fueron los estrategas de la geopolítica anglosajona los que manipularon a Hitler para que desate una guerra que destruya a Europa continental y principalmente a la Unión Soviética, a la misma Alemania y a Francia (en ese orden). El siguiente texto que se reproduce textualmente no deja dudas de lo que se afirma:

"Cuando Hitler anunció a su estado mayor, a fines de 1937, que tenía un programa considerable de anexiones para iniciar el año siguiente con la del territorio de los Sudetes (de habla alemana) de Checoslovaquia, los generales volvieron a poner reparos. El general Ludwig Beck, jefe del estado mayor, pensaba que Inglaterra y Francia acudirían inevitablemente en ayuda de Checoslovaquia. El estado mayor envió un memorando a Hitler expresando sus temores y, como Hitler lo ignoró, Beck dimitió. Algunos generales comenzaron a conspirar para deshacerse del führer ${ }^{13}$, pero al acceder los ingleses y los franceses a sus demandas en Munich, perdieron su punto de apoyo..."

"Aquella actitud permisiva se había manifestado desde el comienzo mismo del liderazgo de Hitler, y contribuyó posiblemente a que este se sintiese tan seguro de sí mismo. Su confianza en que Francia e Inglaterra no harían nada para frustrar sus ambiciones en Europa Oriental recibió una inyección en noviembre de 1937, cuando lord Halifax, lord presidente del Consejo y mano derecha de Chamberlain, le dejó entrever que así sería”.

"Poco después de la visita de Halifax, el embajador inglés en Berlín, sir Neville Henderson, corroboró las palabras de Halifax, y Hitler, no sin razón, pensó que Inglaterra, al fin, consideraba aceptables sus ambiciones territoriales en Europa Oriental" (Chant, Preston, \& Shaw, 1982) $)^{14}$.

Los autores del libro Segunda Guerra Mundial (que acabamos de citar en el párrafo anterior), inconscientemente nos han legado valiosos materiales para deducir e interpretar el sutil manejo de la política por parte de Inglaterra en la década de los treinta del siglo pasado. Su primer y más importante objetivo era destruir a los dos países más grandes e importantes de Europa: la Unión Soviética y Alemania. El primerísimo objetivo era eliminar la amenaza del comunismo en la Unión Soviética. Un segundo momento era lograr la autodestrucción de Alemania. Dar cuenta de Francia y del resto de la Europa eran objetivos secundarios, pero también importantes. Evidentemente Hitler no fue más que un instrumento de Neville Chamberlain (posteriormente de Winston Churchill) y de Franklin D. Roosevelt.

Existía el riesgo que Hitler ataque también a la isla de Bretaña, pero estaba claro que los recursos naturales se encontraban desde Alemania hacia el este. Es decir, estamos afirmando que una invasión por parte de Alemania hacia Inglaterra carecía de sentido y eso la dupla ChamberlainChurchill lo comprendía perfectamente.

13 Los autores del libro que se está citando se refieren al primer atentado en contra de la vida de Hitler perpetrado el 8 de noviembre de 1939.

14 Cabe aclarar que este libro es, por decirlo de alguna manera, una versión inglesa de la guerra. Los autores del mismo libro tergiversan la verdadera historia de la Segunda Guerra Mundial, minimizando el papel jugado por la URSS. Por esta razón, en cambio, las citas que hemos realizado de su libro adquieren mayor relevancia. 
Esta es la lógica que permite comprender por qué Churchill nunca aceptó las reiteradas propuestas de Hitler para invadir juntos a la Unión Soviética. En este caso Inglaterra hubiese puesto muchos muertos innecesarios. Asimismo, existía la posibilidad de derrotar al país soviético, pero no se lograba la autodestrucción de Alemania. El talante de Hitler y de Rudolf Hess ${ }^{15}$ no estaba a la altura del sutil manejo de la política por parte de los ingleses.

En esta parte del análisis conviene traer a colación otros dos hechos que indican la intención de Hitler y su alto mando de lograr acuerdos con los ingleses para derrotar y destruir a la Unión Soviética, se trata de la evacuación de Dunkerque en junio de 1940 y al viaje que realizó Rudolf Hess a Escocia en mayo de 1941.

Para entender la evacuación de Dunkerque es necesario recordar algunos sucesos que dan origen a la Segunda Guerra Mundial.

Oficialmente, la Segunda Guerra Mundial comenzó el 1 de septiembre de 1939, cuando a las 5:35 de la mañana fue bombardeado el Corredor (pasillo) de Danzig ${ }^{16}$. El segundo momento fue la invasión de Noruega y Dinamarca el 9 de abril de 1940. Hitler abandonó Berlín el 9 de mayo de 1940 en su tren privado América, y se dirigió hacia la frontera francesa. Era claro que tenía en la mira a los Países Bajos, Bélgica y Francia. Ante este panorama, Gamelin (Comandante en jefe de las fuerzas terrestres franco-británicas) esperaba enfrentar a los alemanes en tierras belgas $^{17}$. Hitler, en cambio, aceptó el plan de von Manstein de cortar directamente a través de las $\operatorname{Ardenas}^{18}$. La estrategia del alto mando alemán arrasó con los ejércitos franco-británicos, los cuales fueron arrinconados en Dunkerque (Clarke, 2011). Inexplicablemente, Hitler rehusó dar la orden de atacar Dunkerque y permitió que franceses e ingleses sean transportados a playas inglesas $^{19}$. La operación Dínamo se efectuó a finales de mayo de 1940. A propósito de la retirada de Dunkerque, Churchill manifestó "Las guerras no se ganan por evacuación”. (Valdeville, 2012)

¿Por qué la inexplicable actitud de Hitler? Carlos de Nápoli le dedica un capítulo en su libro a este misterio llegando a la siguiente conclusión: "No se trató de un milagro, sino de una tregua pactada entre británicos y alemanes con la mediación de Benito Mussolini...”

"Un avance de las fuerzas alemanas sobre Dunkerque habría sido sencillo, inevitable y fatal. Los británicos estaban rodeados, perdidos, moralmente destruidos, y sin el armamento defensivo necesario para rechazar el ataque. Si Hitler hubiera utilizado sus fuerzas acorazadas, su artillería, sus morteros o la aviación, habría causado una masacre sin precedentes. Evitó exterminar impunemente a los virtualmente indefensos soldados británicos a cambio de un compromiso de paz por parte de Gran Bretaña”.

"Por supuesto el pacto debió ocultarse a todo el mundo, especialmente a los franceses, que sin embargo sospecharon siempre un acuerdo secreto a sus espaldas. A propósito, el falso relato de Churchill sobre la batalla aérea de Dunkerque pretende entre otras cosas atenuar las diferencias entre franceses y británicos ${ }^{20}$, aunque los hechos estaban a la vista: casi de

15 Mencionamos a Rudolf Hess, en vista que era el mayor confidente de Hitler, además de Führer interino, ministro del Reich sin cartera, jefe del partido nazi, miembro del Consejo de Gabinete Secreto de Alemania y miembro del Consejo Ministerial de Defensa del Reich.

16 En este caso también es necesario recordar que en 1919 al firmarse el Tratado de Versalles se dividió el territorio alemán en dos para darle salida al mar a Polonia. (Valdeville, 2012)

17 Charles de Gaulle mantenía reparos con la estrategia de Gamelin. De Gaulle proponía tomar la ofensiva mediante un ataque masivo de tanques.

18 Las Ardenas eran (o son) unas colinas altamente boscosas, razón por la cual los franceses no las custodiaban.

19 "El almirante Bertram Ramsey planeó la operación, llamada Dínamo, en la que fueron recogidos de las playas cercadas cerca de 338 mil hombres, incluyendo 113 mil franceses". (Chant, Preston, \& Shaw, 1982)

20 Carlos de Nápoli se refiere a relatos que realiza Churchill sobre supuestos bombardeos de la aviación inglesa en las playas de Dunkerque. Esto lo relata Churchill en su libro La Segunda Guerra Mundial. 
inmediato, miles de franceses evacuados al Reino Unido fueron devueltos nuevamente a su tierra, abandonados a su suerte en diferentes puntos de la costa, desarmados, listos para ser capturados por los nazis. Se trataba de la parte siniestra del pacto Hitler-Churchill, que no incluía la salvaguarda del ejército aliado continental. Muchos franceses fueron fusilados, mientras que la mayoría terminó como mano de obra esclava en campos de concentración”. (De Nápoli, 2015)

La versión de Churchill sobre este acontecimiento linda con la fantasía. En el libro que escribió sobre la Segunda Guerra Mundial, relata incesantes bombardeos por parte de los alemanes en las playas de Dunkerque (Churchill, 1958). Lo sorprendente es que los soldados ingleses y franceses nunca presenciaron el bombardeo del que eran objeto.

El caso de Rudolf Hess es más difícil de tratar. Todo es misterio y conjeturas. Aterrizó en Escocia entre el 10 y el 11 de mayo de 1941. La fecha tiene superlativa importancia, pues la operación Barbarroja $^{21}$ estaba ad portas. Un sinnúmero de investigaciones que se han realizado llegan a la siguiente conclusión: Hess fue enviado por el propio Hitler para que negocie un armisticio de dos meses con Inglaterra, tiempo que unos y otros consideraban suficiente para que el ejército alemán haya tomado Moscú. Todo parece indicar que los alemanes pretendían negociar direc- tamente con la monarquía inglesa, pues Hitler no confiaba en Churchill ${ }^{22}$. En todo caso, sería ingenuo pensar que Hess huyó a Escocia por motu proprio.

Negociando con Churchill o con la monarquía inglesa, la estrategia de Hitler consistía en obtener carta blanca para invadir a la Unión Soviética. Para ello debía asegurarse que el Reino Unido no invadiría Francia cuando sus tropas se dirigieran hacia las estepas del este.

“Como opción de máxima Hitler acuñaba la posibilidad de un ataque conjunto a la Unión Soviética. Con Churchill en el gobierno, un furioso anticomunista, no era imposible. Von Ribbentrop y Churchill lo habían discutido antes". (De Nápoli, 2015)

\section{Conclusión}

En la Segunda Guerra Mundial Alemania no combatió en dos frentes, combatió en un solo frente: al este del Rhin. Cierto es, también hubo algunas escaramuzas en el África septentrional. Este es el tenebroso contexto que antecede y explica el Plan Barbarroja. Un elemento no tomaron en cuenta los Estados Unidos, Inglaterra y Alemania: Que la Revolución Rusa había creado una poderosa identidad nacional llamada Unión de Repúblicas Socialistas Soviéticas. Esos son los hechos.

21 La operación Barbarrosa o Barbarroja se refiere a la invasión de Alemania a territorios de la Unión Soviética el 22 de junio de 1941. Toma el nombre del emperador medieval Federico Barbarrosa.

22 Queda para la anécdota los términos que utilizaba Hitler para referirse a Churchill. Unos días lo tildaba de judio agobiado, otros en cambio de ebrio medio americano. 


\section{Referencias bibliográficas}

- Brook, G. (Enero 1977). Anschluss: The Rape of Austria. London: Palgrane Macmillan U.K.

- Bueno, R. (1985). La Guerra en Europa. 19391945. Quito, Ecuador: Ediciones Culturales UNP S.A.

- Chant, C., Preston, A., \& Shaw, J. (1982). Segunda Guerra Mundial. Barcelona: Círculo de lectores.

- Churchill, W. S. (1958). La Segunda Guerra Mundial. Buenos Aires: Peuser.

- Clarke, I. (2011). Apocalypse, The Second World War.

- De Nápoli, C. (2015). Elpacto Churchill Hitler. Buenos Aires: Ediciones B Argentina.

- Dornbusch, R., Stanley, F., \& Richard, S. (2002). MACROECONOMÍA (Octava Edición ed.). (E. Rabasco, \& L. Toharia, Trads.) España: McWRAW-HILL.
- Katasonov, V. (16 de mayo de 2015). Banqueros anglosajones organizaron la Segunda Guerra Mundial. Recuperado el 23 de mayo de 2015, de http://www.bankofengland.co.uk/arch

- Keynes, J. M. (junio de 2002). Las consecuencias económicas de la paz. Madrid: Biblioteca de Bolsillo.

- Krugman, P. R. (1999). De vuelta a la economía de la Gran Depresión. Santa Fe de Bogotá: Grupo Editorial Norma.

- Nietzsche, F. (abril 2009). La voluntad de poder. España: Biblioteca Edaf.

- Soloviov, B. (1988). La Batalla de Kursk. Agencia de prensa Nóvosti.

- Valdeville, L. (Dirección). (2012). Apocalipsis [Película].

- Zhukov, G. (1971). Memorias y Reflexiones. La Habana: Instituto Cubano del libro. 